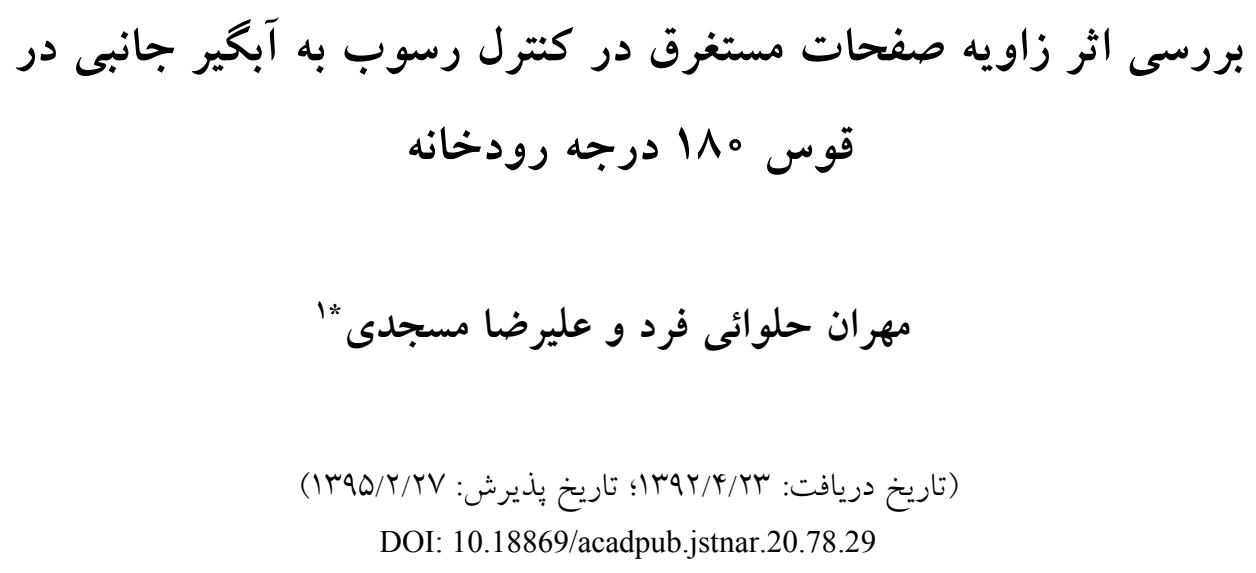

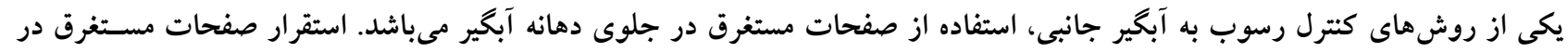

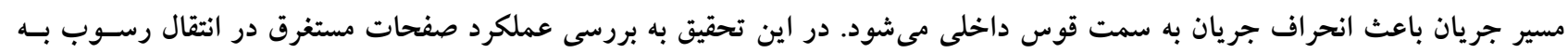

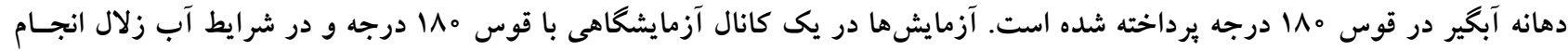

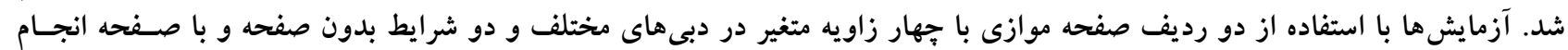

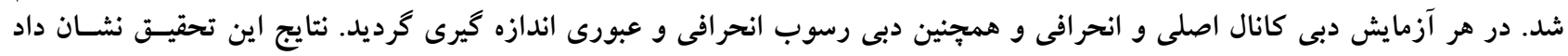

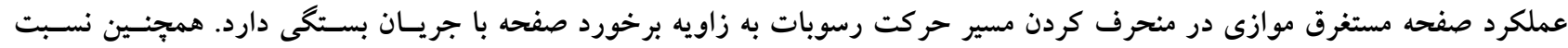

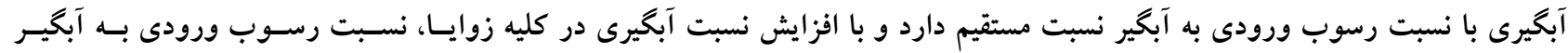

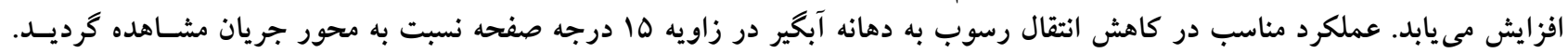

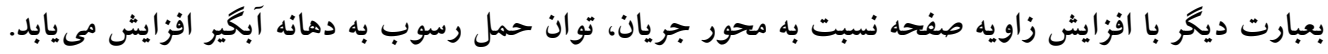

كلمات كليدى: آبخير جانبى، آب زلال، صفحه مستغرق، قوس •1ا درجه 
حركت مارييجى در آمده و باعث تغييرات در تنش برشى بسـتر

مقدمه

و تويوكرافى كف رودخانه مىشوند. (ه).

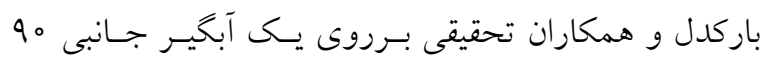

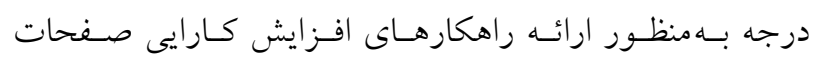

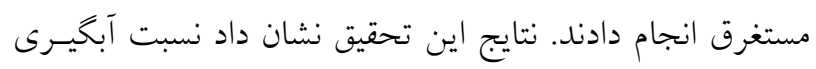

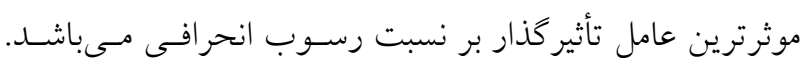

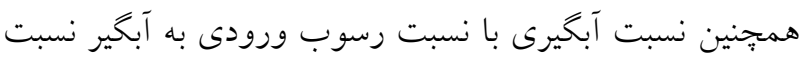

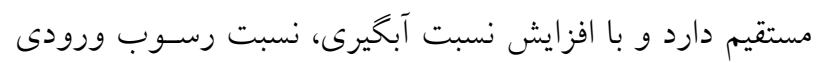
به آبخير افزايش مىيابد (†). ويزگكىهاى حركت جريان و رسـوب اطـراف يـك صـفحه

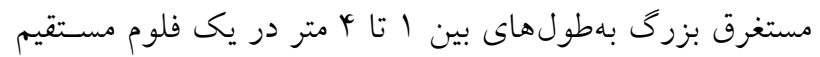
و عريض بهطول ه广متر و عرض 9 متر، توسط تن و همكـاران مورد بررسى قرار كرفت. اين تحقيق نشان داد كه كارايى صفحه

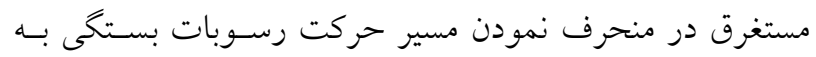
زاويه برخورد صفحه با جريان، ارتفاع و طول صفحه دارد (9).

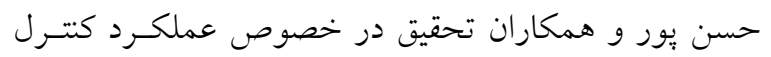

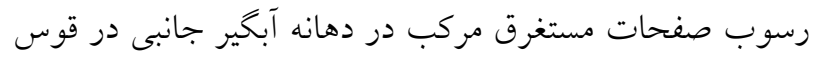

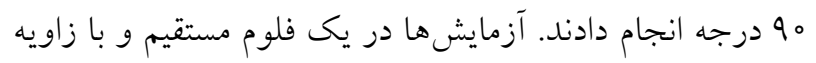

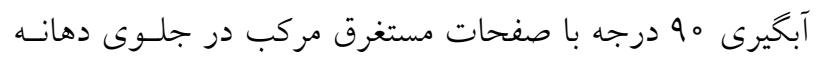

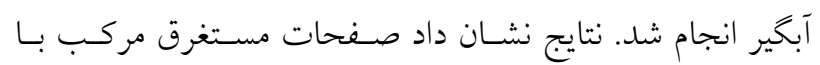

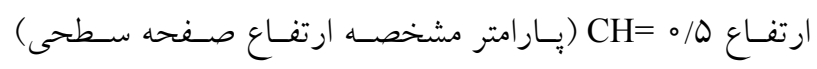

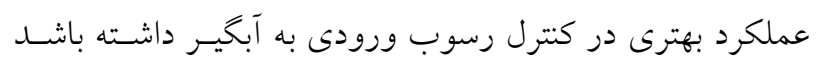

نظرى و همكاران نيز تحقيقى برروى تـأثير زاويـهـ انحـراف

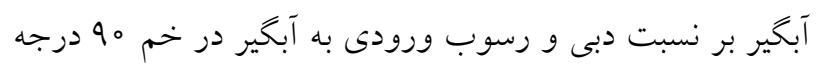

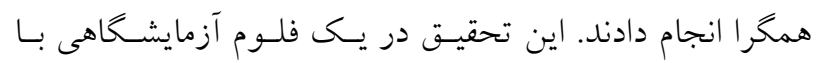

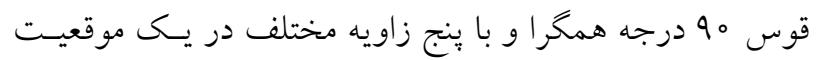
از قوس انجام شد. نتايج اين تحقيق نشـان داد حــاقل رسـوب

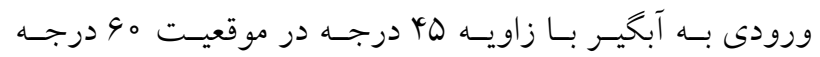

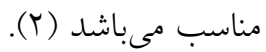

تحقيقات انجام شــه در كذشـته نشـان مسدهـــ صـفحات مستغرق بهعنوان سازهاى مؤثر براى كتــــ رسـوب ورودى بــهـ
در قوس رودخانه بهدليل وجود جريانهاى ثانويه مـواد رسـوبى

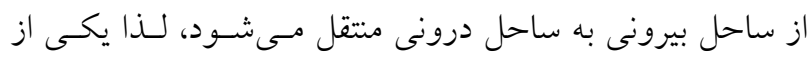

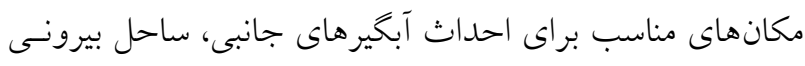
قوس رودخانه مىباشد.

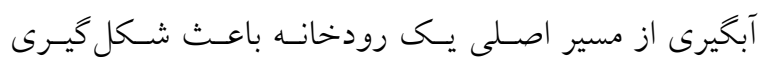

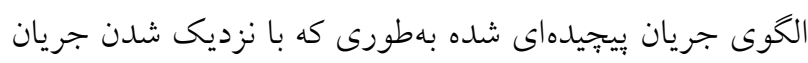

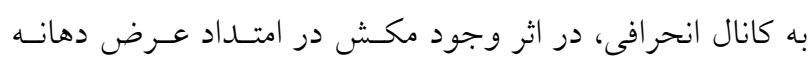

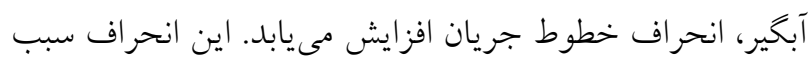

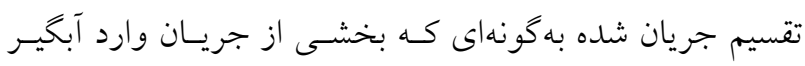

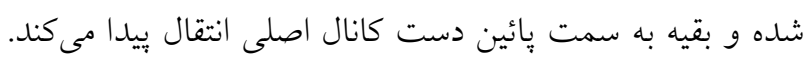

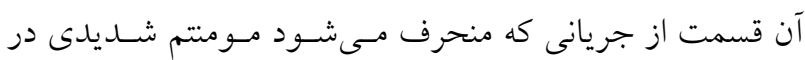

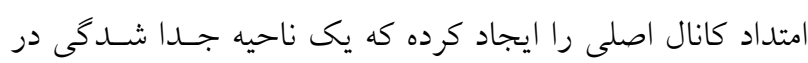

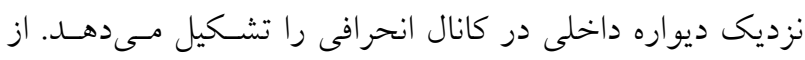

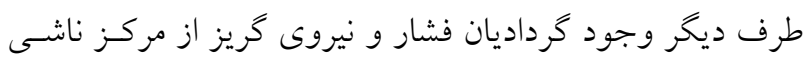
از خطوط انحناى جريان، موجب عدم تعادل در الحــوى جريـان ورودى به آبخير مى شود.

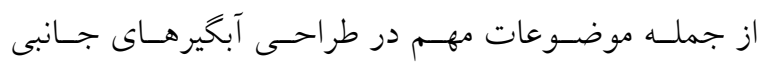

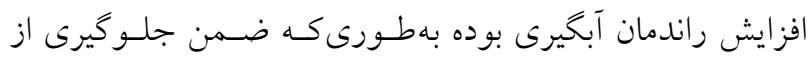

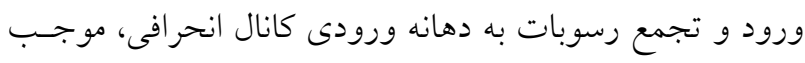

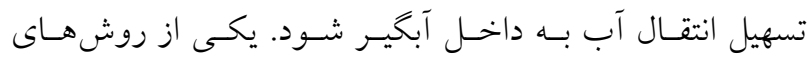

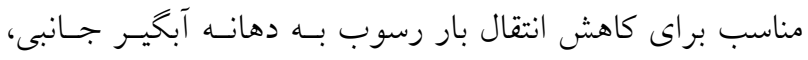

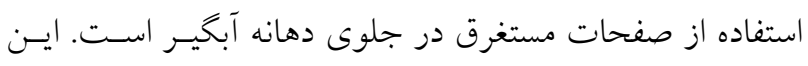

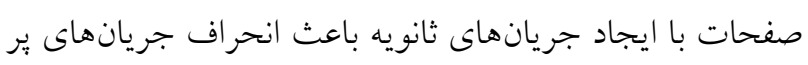

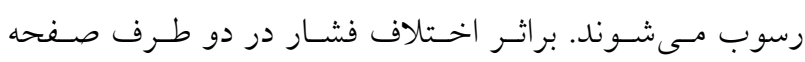

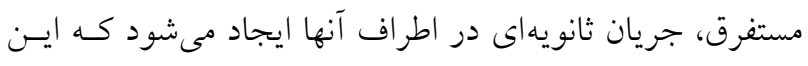

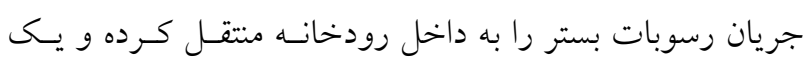

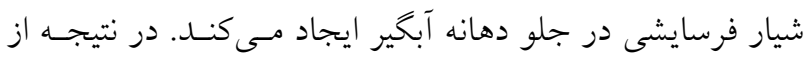

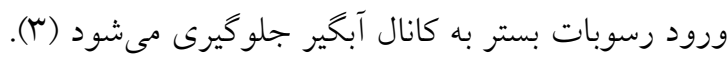

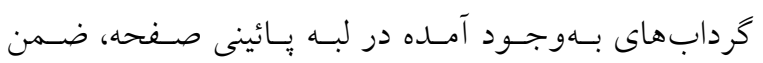

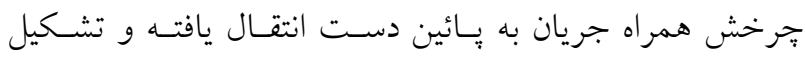

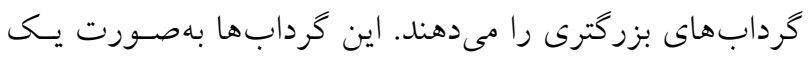




$$
\mathrm{f}\left(\mathrm{Fr}, \mathrm{Q}_{\mathrm{r}}, \mathrm{Q}_{\mathrm{Sr}}, \beta\right)=0
$$

ع $\mathrm{Fr}=\mathrm{Q}_{\mathrm{M}} / \mathrm{B} \sqrt{\mathrm{gyr}}(\mathrm{r})$ בر معادلـ

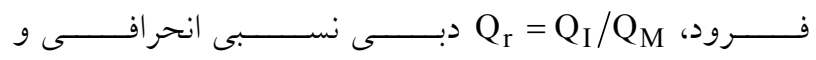
دبى رسوب انحر افى مى باشـد. در $\mathrm{Q}_{\mathrm{Sr}}=\mathrm{Q}_{\mathrm{SI}} /\left(\mathrm{Q}_{\mathrm{SM}}+\mathrm{Q}_{\mathrm{SI}}\right)$ كليه آزمايشها بـا توجـهـ بــه آشـفتكى جريـان، جريـان از نـوع متلاطم بوده و عدد رينولدز حذف گرديد. آزمايش هاى اين تحقيق بهصورت هيدروليكى و با رسـوبات بستر با نصب صـفحات مسـتغرق بـا آرايسش مـنظم در زوايـاى

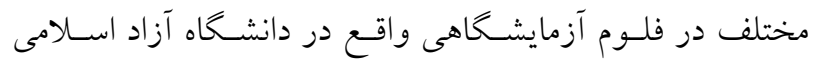
واحد اهواز انجـام شـــ. صـفحات مسـتغرق از جـنس يِلكسى كالس با ضخامت r ميلى متر ساخته شده و در دو رديف طـولى در جلوى دهانه آبخير نصب گرديدند. كانال اصلى با عرض سـانتى متــر، شـعاع مركـزى T/A متــر و انحنــاى نسـبى قـوس

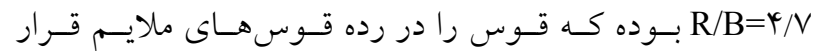
مى دهد. بهمنظور جلو گيرى از ورود امـواج مستلاطم بـه قـوس، كانال مستقيم ورودى بنهول 1/9 متر به يك كانال با قوس 11/ درجه متصل كرديد. اين كانال قوسى شكل توسط كانال مستقيم

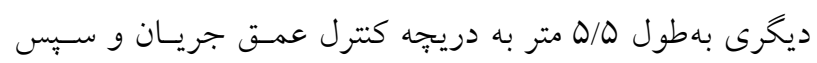

مخزن خروجى متصل مىشود (شكل (1).

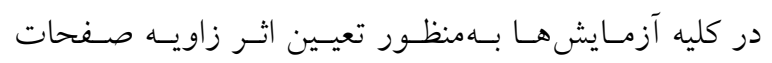
مستغرق بر كنترل رسوبات ورودى به آبخير طبق توصيه ادگار و كندى آزمايش ها در جهـار زاويسه متفـاوت صـفحات مسـتغرق

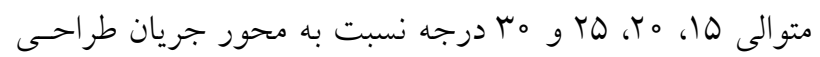
و اجرا گرديد (و). با توجه به اينكـه آب شستـى موضسعى در شرايط آب زلال انجام شد، لذا بهمنظور جلو گيرى از فرسايش و انتقال رسوبات در بالا دست صفحات، سرعت متوسـط جريـان بايد كمتر از سرعت بحرانى (u< u u باشد. در كليه آزمايشهـا نسبت سرعت برشى بـه سـرعت برشى بحرانسى بـا اسـتفاده از

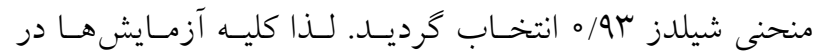

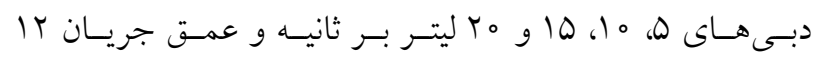

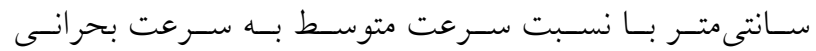

آبخير مىباشد. با توجه بـهـ ايسنـــه الخـوى جريـان و تغييـرات سرعت در محدوده آبخيرهاى جانبى متصل به كانالهاى مستقيم يبيجيده و سه بعدى مىباشد. در صورتى كه اين آبخيرهـا بـرورى كانالهــاى قوسـى احـــاث شـوند، بـهدليـل الخــوى جريـان در قوسها، اين وضعيت بيتيجيدهتر خواهد شد. لذا نيـاز بـهـ تحقيـق بيشتر در خصوص تأثير زاويه و علدد فـرود در عملكـرد كتتـرل رسوب ورودى به آبخير در قوس م^ا درجه است.

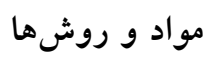
در مدلسازى جريان برروى يك آبخير جانبى، مهمتـرين هـدف تعيين مقدار دبى منحرف شده و رسوب انحرافى بـه آبخيـر در شرايط مختلف جريان در كانال اصلى اسـت. بـا درنظـر حـرفتن جريان دائمى متغيرهاى مؤثر در ميزان رسوبات ورودى به آبخير جانبى عبارتند از: - جان $\mathrm{f}\left(\begin{array}{l}\mathrm{Q}_{\mathrm{SI}}, \mathrm{Q}_{\mathrm{SM}}, \mathrm{Q}_{\mathrm{M}}, \mathrm{Q}_{\mathrm{I}}, \mathrm{y}, \mathrm{B}, \mathrm{R}, \mathrm{S}, \mathrm{d} \Delta \circ, \mathrm{g}, \rho, \rho_{\mathrm{s}}, \\ \alpha, \theta, \mu, \mathrm{H}, \mathrm{L}, \mathrm{N}, \beta, \delta_{\mathrm{s}}, \delta_{\mathrm{n}}, \delta_{\mathrm{b}}\end{array}\right)=。$ در رابطه (1)، دبى دسوبات ورودى بـه كانـال آبخيـر، Qبى بار بستر پِائين دست كانال اصلى، Q Q Q Qبى جريـان در كانال اصلى، QI دبى جريان در كانال آبخير، y عمق جريان در كانـال اصـلى، B عـرض كانـال اصـلى، R شـعاع مركـزى قوس، S شيب كانـال اصـلى، do قطـر متوسـط بــار بسـتر، g شتاب ثقل، م جرم مخصوص سيال، م جرم حجمى رسوبات،

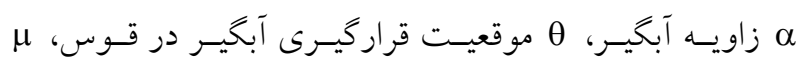
لزجت سيال، H ارتفاع صفحه مسـتغرق، L طـول صـفحه، تعداد رديف صفحات، م زاويه صفحات مستغرق با جريان،

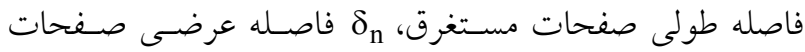
مستغرق و ل فاصله عرضى اولين رديف صفحات مستغرق از دهانه آبخير مىباشند. با صرفنظر كردن از يارامترهاى ثابـت در معادله (1)، معادله زير بهدست مى آيد: $\mathrm{f}\left(\mathrm{Q}_{\mathrm{SI}}, \mathrm{Q}_{\mathrm{SM}}, \mathrm{Q}_{\mathrm{M}}, \mathrm{Q}_{\mathrm{I}}, \mathrm{g}, \mathrm{y}, \beta\right)=。$ با استفاده از تئورى باكينخهام رابطه (Y) بهصورت زير بلدون

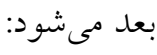




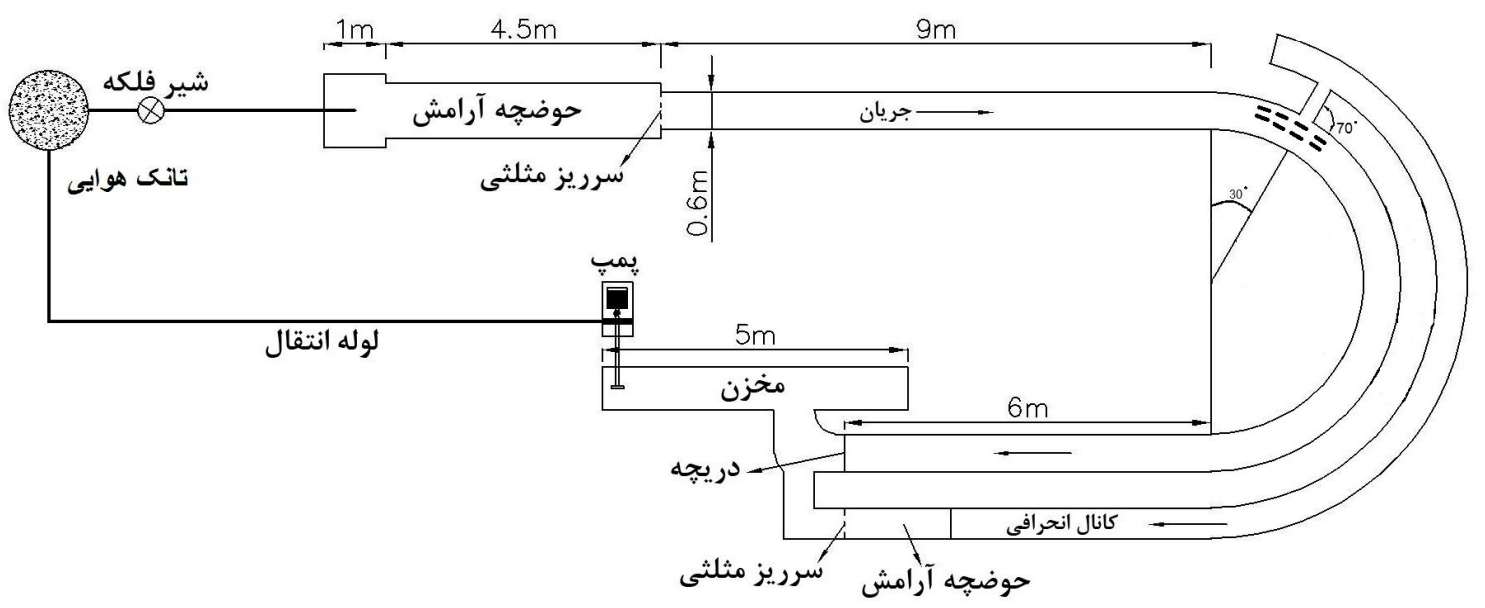

شكل ا. يَان كانال قوسى شكل

جدول ا. مشخصات صفحات مستغرق موازى

\begin{tabular}{|c|c|c|c|c|c|c|}
\hline 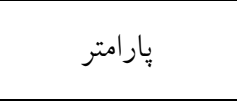 & $\begin{array}{l}\beta \\
(\mathrm{deg})\end{array}$ & $\begin{array}{l}\mathrm{H} \\
(\mathrm{cm})\end{array}$ & $\begin{array}{l}\mathrm{L} \\
(\mathrm{cm})\end{array}$ & $\begin{array}{l}\delta_{\mathrm{s}} \\
(\mathrm{cm})\end{array}$ & $\begin{array}{l}\delta_{\mathrm{n}} \\
(\mathrm{cm})\end{array}$ & $\begin{array}{l}\delta_{\mathrm{b}} \\
(\mathrm{cm})\end{array}$ \\
\hline محدوده توصيهشده & $10 \leq \beta \leq r \Delta$ & $0, r \leq \mathrm{H} / \mathrm{y} \leq 0,0$ & $r \mathrm{H} \leq \mathrm{L} \leq \boldsymbol{r} \mathrm{H}$ & $\wedge \mathrm{H} \leq \delta_{\mathrm{s}} \leq \mathrm{\iota} \bullet \mathrm{H}$ & $r H \leq \delta_{n} \leq r H$ & rH \\
\hline محدوده بهكار رفته & 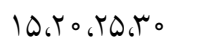 & $\circ / \mu_{y}$ & r $\mathrm{H}$ & $\wedge \mathrm{H}$ & r $\mathrm{H}$ & r $\mathrm{H}$ \\
\hline اندازه بهكار رفته & 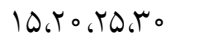 & $r / 9$ & $10 / 1$ & TN/A & $10 / 1$ & $10 / 1$ \\
\hline
\end{tabular}

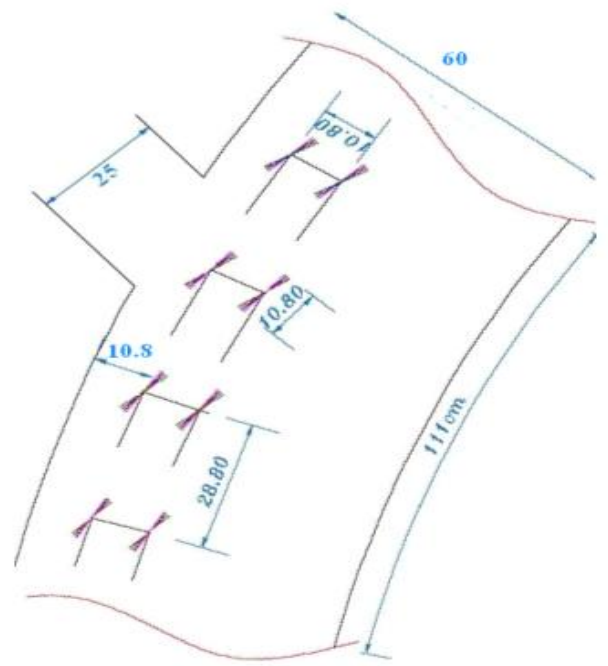

شكل r. مشخصات صفحات مستغرق موازى در فلوم آزمايشگاهى

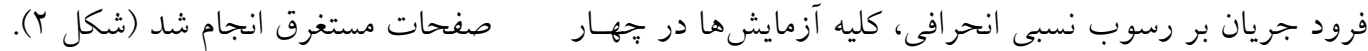

از آنجائى كه در آزمايش هـا هـدف بررسسى درصـد رسـوب

انحرافى مىباشد لذا زمان آزمايش به گونهاى انتخاب كرديد كـه حركت رسوبات به آبخير و به پِيأين دست كانال اصلى به حالت

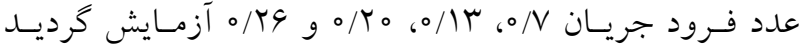
(جدول (). كليه آزمايشها در موقعيت •ب در قوس •ما درجه و زاويه آبخيرى V0 درجه در شرايط با حضور صفحات و بدون 
سرريز لبه تيز مثلثى در ابتداى كانال قوسى شكل اصسلى بعـــ از

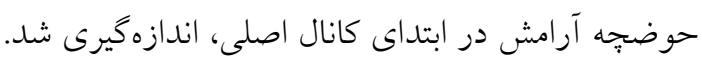

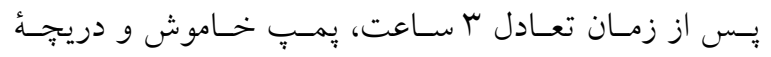

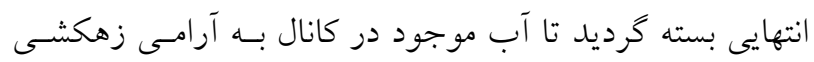

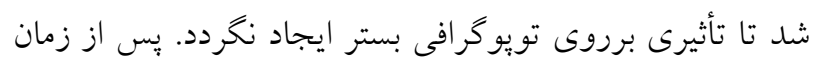

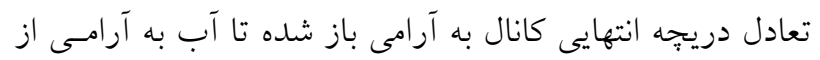

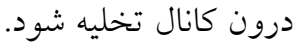

\section{نتايج و بحث}

در كليه آزمايشها پِّ از تنظيم دبى و عمق جريـان، بلافاصسله

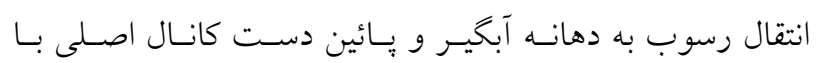

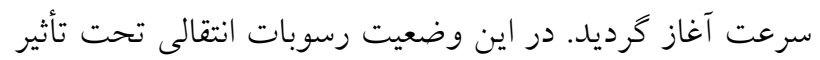

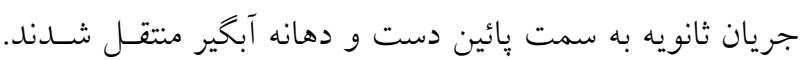

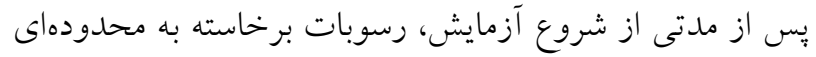

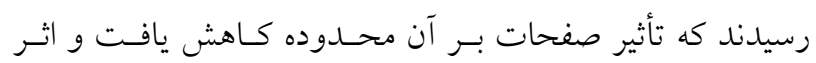

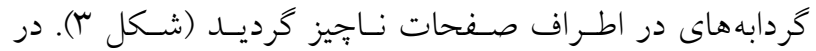
انتهاى هر آزمايش مقــادير رسـوب عبسورى در كانـال اصسلى و

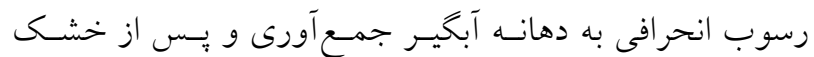

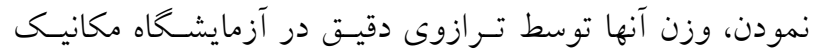

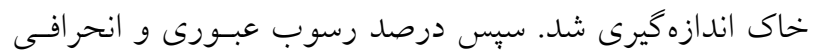

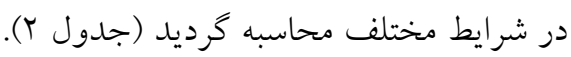

تأثيرعدد فرود جريان بالا دسـت كانـال اصسلى بـر نسـبت رسوب انحرافـى در شـرايط بـا صـفحه و بــدون صـفحات مستغرق شكل (4) نمودار بلدون بعد درصــ نسـبت رسـوب انحرافـى و عدد فرود جريان بالا دست كانال اصلى در شرايط عدم نصب و

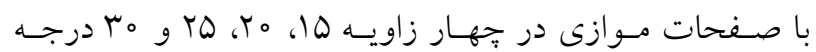

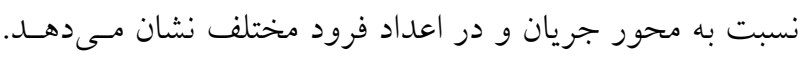
عدد فرود با نسبت رسوب ورودى به آبخير نسبت عكس دارد و

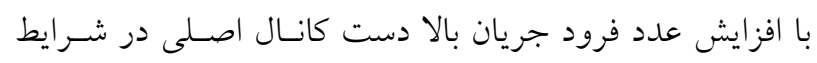

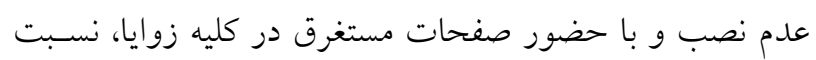

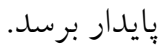

به توصيه راودكيوى و اتما براى جلو كيرى از تشكيل رييـل

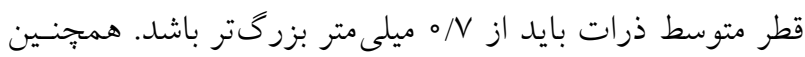

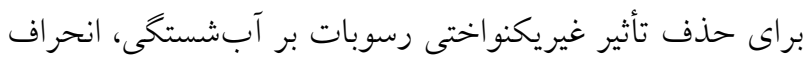

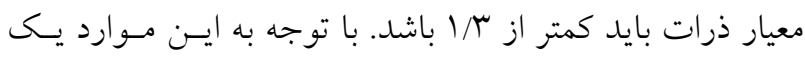

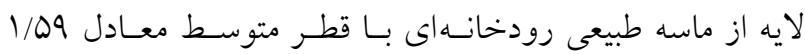

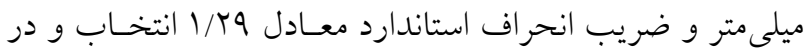
لايهاى به ضخامت تقريبى ه ا سانتىمتر جهت انجام آزمايشهـا

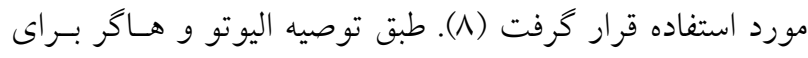

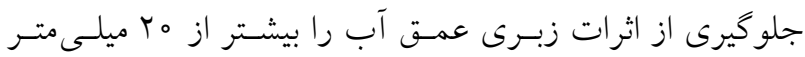

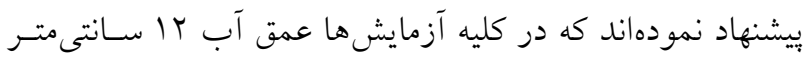

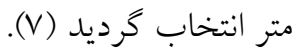
بهمنظور تعيين زمان تعادل آزمايشها، يك آزمايش طـولانى بهمدت r ا ساعت برروى آبخير بدون حضور صفحات مستغرق

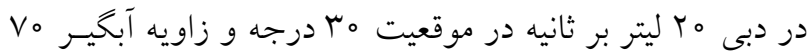

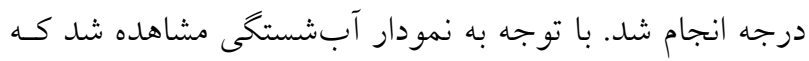

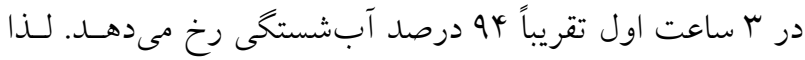
در كليه آزمايشها، زمان تعادل ب ساعت درنظر كرفته شد.

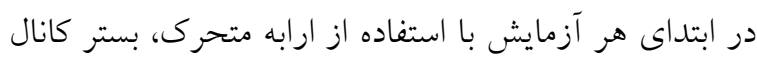

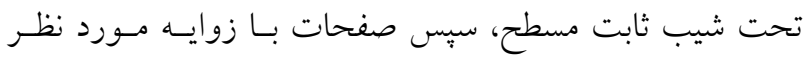

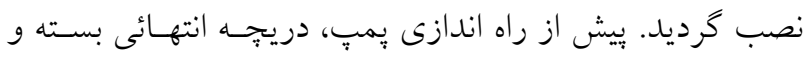

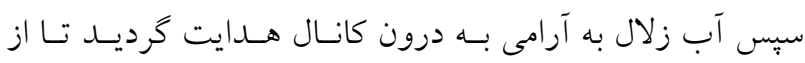

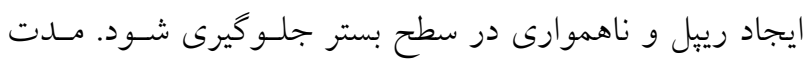

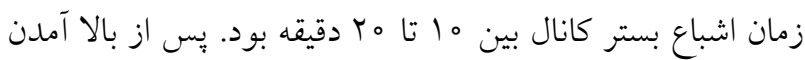

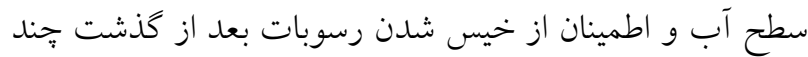

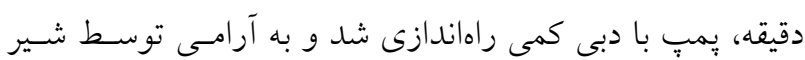

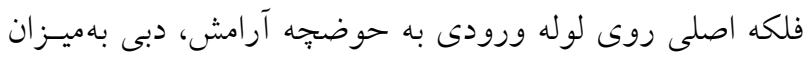
مورد نظر تنظيم شد. سبس با تنظيم دقيق و همزمان شسيرفلكه و دريجه يائين دست عمق جريان I| سانتىمتر و دبس مـوردنظـر

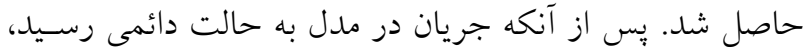
مقدار دبى انحرافى توسط سـرريز لبـهـ تيـز مثلثـى در انتهـاى

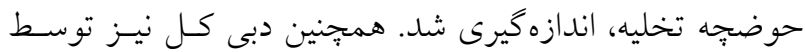


جدول r. نتايج حاصل از دبى و رسوب نسبى در زواياى مختلف صفحات مستغرق

\begin{tabular}{|c|c|c|c|c|c|c|c|c|}
\hline $\begin{array}{l}\beta \\
(\mathrm{deg})\end{array}$ & $\begin{array}{l}\mathrm{Q}_{\mathrm{I}} \\
(\mathrm{Lit} / \mathrm{s})\end{array}$ & $\begin{array}{l}\mathrm{Q}_{\mathrm{M}} \\
(\mathrm{Lit} / \mathrm{s})\end{array}$ & $\begin{array}{l}\mathrm{Q}_{\mathrm{r}} \\
(\%)\end{array}$ & $\begin{array}{l}\mathrm{Q}_{\mathrm{SI}} \\
(\mathrm{gr} / \mathrm{s})\end{array}$ & $\begin{array}{l}\mathrm{Q}_{\mathrm{SM}} \\
(\mathrm{gr} / \mathrm{s})\end{array}$ & $\begin{array}{l}\mathrm{Q}_{\mathrm{SM}}+\mathrm{Q}_{\mathrm{SI}} \\
(\mathrm{gr} / \mathrm{s})\end{array}$ & $\begin{array}{c}\mathrm{Q}_{\mathrm{Sr}} \\
(\%)\end{array}$ & $\mathrm{Fr}$ \\
\hline 10 & $r / 4 q$ & 0 & $r q / \Lambda r$ & $\Delta F \wedge$ & $9 \vee 0$ & 1011 & $r_{4} / 10$ & $\circ / 0 \mathrm{~V}$ \\
\hline 10 & $r / 90$ & 10 & MG/4G & 110 & $10 \circ 0$ & סוזץ & $r \Delta / r \mid$ & سות \\
\hline 10 & YNY & 10 & 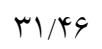 & ITGY & rDS。 & MNTY & $r \Delta / \circ r$ & $0 / Y_{0}$ \\
\hline 10 & $D / K Y$ & ro & TV/TY & $1 \wedge 90$ & ras。 & $\Delta \wedge \psi_{0}$ & M/AD & $0 / K G$ \\
\hline ro & $r / 90$ & 0 & $\Delta r / \circ r$ & 900 & 1000 & 1900 & $\mathrm{rV} / \mathrm{Q} \circ$ & $\% / 0 \mathrm{~V}$ \\
\hline ro & $\varphi / \circ \Delta$ & 10 & $\varphi \circ / \Delta 0$ & 900 & IOTY & Tytr & $\mathrm{rV} / 01$ & سו/. \\
\hline ro & $Q / \circ V$ & 10 & T/AT & lor。 & TVDD & KYAD & $r \Delta / v i$ & $0 / Y_{0}$ \\
\hline ro & $9 / \pi \mu$ & ro & M & Yolo & ऍ^९V & $\Delta \wedge V V$ & $M \mu / T_{0}$ & $0 / K G$ \\
\hline ro & $r / 99$ & 0 & $\Delta Q / \Lambda T$ & $v Q_{0}$ & $q$ qro & IVT。 & $r \Delta / q r$ & $\circ / V$ \\
\hline TQ & $4 / 90$ & 10 & $49 / 04$ & 1109 & אזאו & rQAQ & $\langle 4 / 90$ & س// \\
\hline rQ & Q/A & 10 & MN/AG & $1 \wedge \Delta \Delta$ & TQS. & pylo & $Y Y / O Y$ & $0 / Y_{0}$ \\
\hline TO & $9 / 9)^{4}$ & ro & $\mu \psi / 9 \Lambda$ & TrVG & MTS & $\Delta \varphi_{0} 1$ & $k \circ / 94$ & $0 / K G$ \\
\hline$\mu_{0}$ & $T / N T$ & 0 & $\Delta F / 9 \Lambda$ & IKYo & $M \Lambda \circ$ & مा & & $\circ / 0 \mathrm{~V}$ \\
\hline$\mu_{0}$ & $\uparrow / \Lambda$ & 10 & qr/vq & Trus. & my o & $\Delta \varphi \wedge 。$ & $\psi_{1 / K}$ & سות \\
\hline r。 & $\mathrm{Q} / \mathrm{QV}$ & 10 & $r v / \mu$ & TOVV & ra99 & $90 \mathrm{Vr}$ & $r q / r l$ & $0 / K_{0}$ \\
\hline$\mu_{0}$ & G/Vq & ro & m/9q & ها & $\Delta \circ \circ \Delta$ & NITo & MN/RG & $0 / K G$ \\
\hline
\end{tabular}

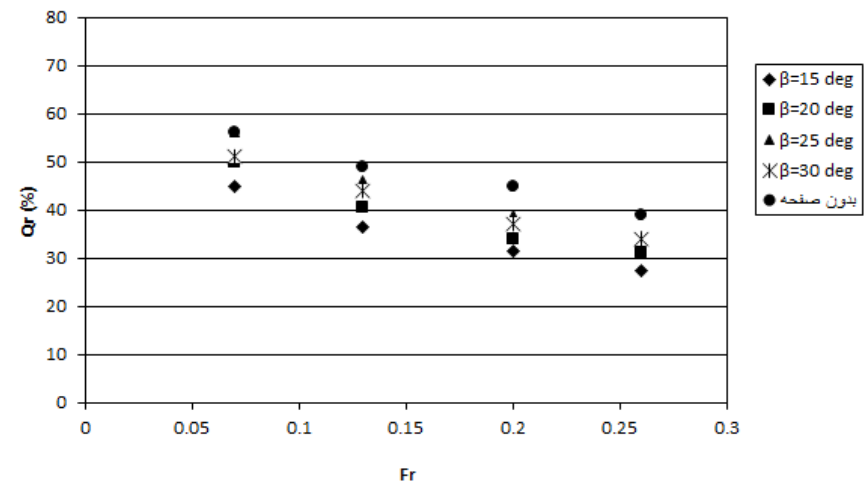

شكل ץ. تأثير عدد فرود جريان بالا دست كانال اصلى بر نسبت رسوب انحر افى در شرايط با صفحه و بدون صفحات مستغرق

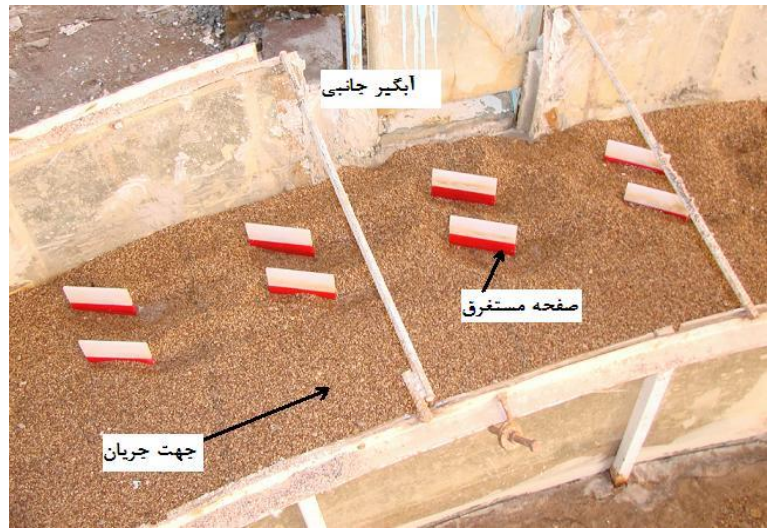

شكل r. صفحات مستغرق در جلوى دهانه آبخير
كانال اصلى در اعداد فرود بيشتر سبب تأثير گذارى كمتـر دهانـه

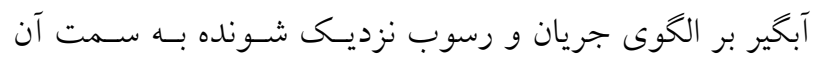
مىشود و در نتيجه رسوبات كمترى وارد آبخير مى بـودي.

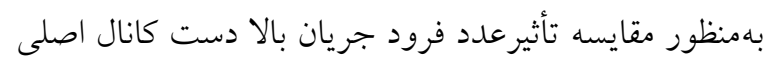

رسوب ورودى به آبخير كاهش مى يابد. افززايش عـدد فـرود در

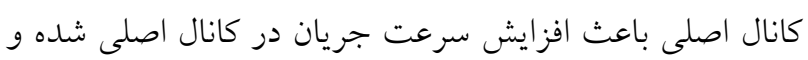
در نتيجه باعث افزايش توان حمل رسوب به بايين دست كاعت كانسال

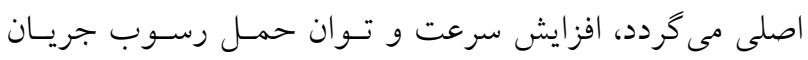




\begin{tabular}{|c|c|c|c|c|}
\hline $\mathrm{Fr}=0 / \Upsilon 4$ & $\mathrm{Fr}=0 / \mathrm{Y}_{0}$ & $\mathrm{Fr}=0 / / r$ & $\mathrm{Fr}=\circ / \mathrm{V}$ & بِار امتر \\
\hline M & rq & TG & rQ & درجه 10 = \\
\hline TG & r & Yr & Tr & درجه م \\
\hline IT & 10 & 9 & 0 & درجه ه =r \\
\hline IV & 19 & Ir & 11 & درجه مبا \\
\hline
\end{tabular}

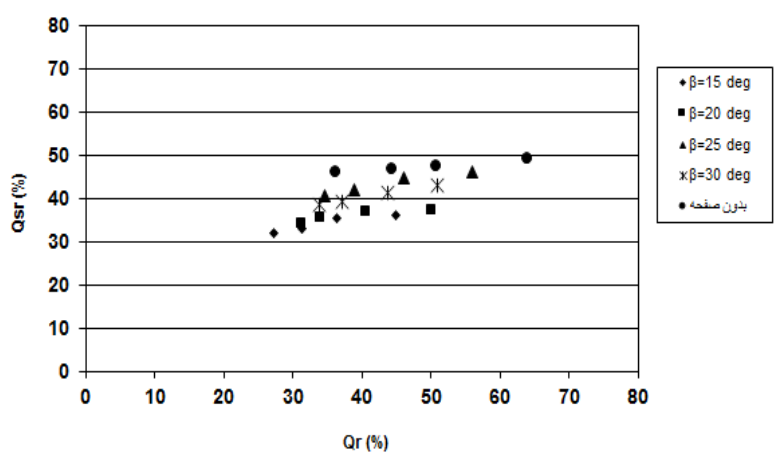

شكل \&. نسبت رسوب انحرافى در شرايط عدم نصب و نصب صفحات مستغرق موازى

مىباشد و در كليه زواياى صفحات مسـتغرق، نسـبت آبخيـر بـاــا نسبت رسوب ورودى بـه آبخيـر در شـرايط عـدم نصـب و بـا صـفحات مسـتغرق نسـبت مسـتقيم دارد و بـا افـزايش نسـبت آبخيرى، نسبت رسوب ورودى بـه آبخيــر افـزايش مسىيابـد. در حقيقت افزايش نسبت آبخيـرى باعـث انحــراف بيشـتر جريـان

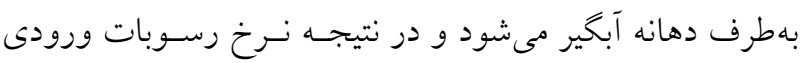

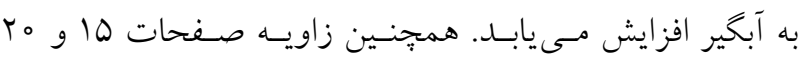
درجسه كمتـرين نسـبت رسـوب انحرافـى و ه广و هم درجسه بيشترين نسبت رسوب انحر افى مشاهله مىشود. بهعبارت ديخر با افزايش زاويه صفحه نسـبت بـه محسور جريـان، تـوان حمـل رسوب به دهانه آبخير افزايش مى يابد.

درصد كاهش رسوب انحرافى با صفحات مستغرق نسبت بــه بدون صفحه جدول (r) درصد كاهش رسوب انحرافـى بـه دهانـه آبخيـر بـا صفحات نسبت بهحالت بدون صفحه براى جهار زاويه صفحات

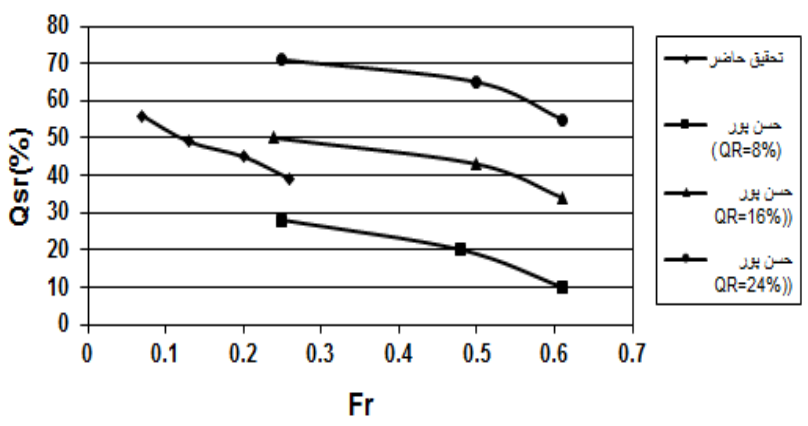

شكل ه. مقايسه تأثيرعدد فرود جريان بالا دست كانال اصلى بر درصد رسوب انحرافى در شرايط بدون صفحات مستغرق در تحقيق حاضر با ساير محققين

بر درصد رسوب انحرافى در شرايط بدون صفحات مستغرق در تحقيق حاضر با ساير محققين، از نتايج تحقيقات حسـن يـور و

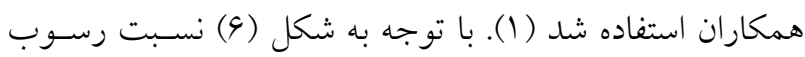
انحرافى براى اعداد فرود مختلف اين تحقيق با نتايج تحقيقـات

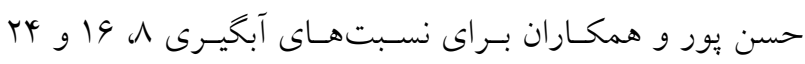
درصد مقايسه كرديـــ ( (1). مقايسـه نتـايج تأييـد كنــده كـاهش رسوب انحرافى در اثر افزايش عدد فرود جريان بالا دست كانال

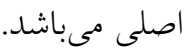

نسبت رسـوب انحرافـى در شـرايط عـدم نصـب و نصـب صفحات مستغرق موازى شكل (9) نمودار بــدون بعـــ درصـد نسـبت آبخيـرى و نسـبت رسوب انحرافى در شرايط عدم نصب و با صـفحات مـوازى در

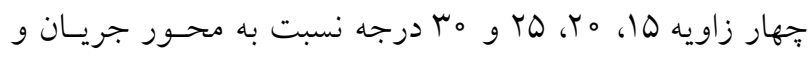
در اعداد فرود مختلف نشان مى دهـــ. همـان كونـه كـهـ مشـاهده

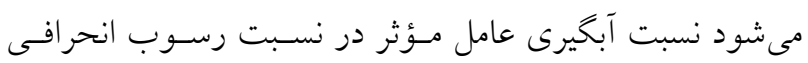


با حضـور صـفحات مسـتغرق در كليـه زوايـا، نسـبت رسـوب ورودى به آبخير كاهش مى يابد. نسبت آبخيـرى عامـل مـؤثر در نسبت رسوب انحرافى مسىباشــ و در كليـه زوايـاى صـفحات

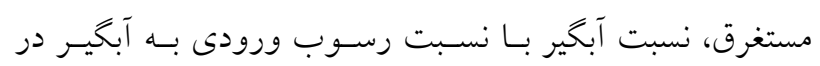
شر ايط عدم نصب و با صفحات مستغرق نسبت مسـتقيم دارد و با افـزايش نسـبت آبخيـرى، نسـبت رسـوب وروديى بـه آبخيـر افزايش مىيابد. زاويه صفحات ها و مب درجه بيشترين درصـد كاهش رسوب انحرافى و هY و مr درجه كمترين درصد كاهش

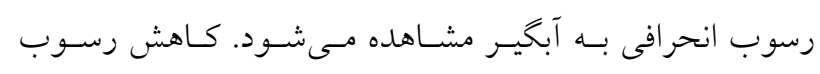

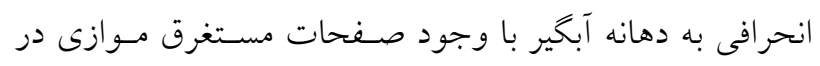

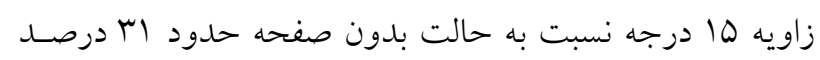

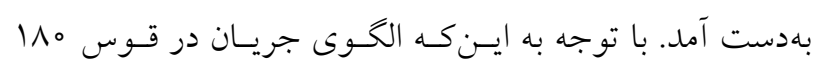

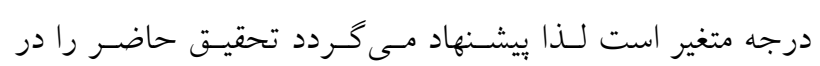
موقعيتهاى ديخر در طول قوس انجام داده و نتايج آنرا با نتايج حاضر مقايسه نمود.

\section{سباسگز ارى}

از مساعدت مسئولين محترم دانشخاه آزاد اسلامى واحـــ اهــواز بهمنظور قرار دادن امكانات، تسهيلات و كمكىهاى مالى در ايسن تحقيق تشكر و قدردانى مىشود.
مستغرق موازى و جهار عدد فرود نشان داده شده اسـت. نتسايج نشان مىدهد زاويه صفحات ها و مب درجـهـ بيشـترين درصــ كاهش رسوب انحرافى و ها و مب درجه كمترين درصد كاهش رسوب انحرافى به آبخيـر مشـاهده مسى شـود. همجِنسين كـاهش رسوب انحرافى به دهانـه آبخيـر بـا وجـود صـفحات مسـتغرق

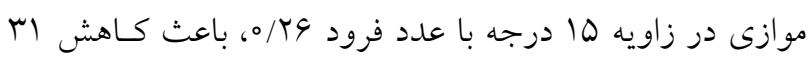

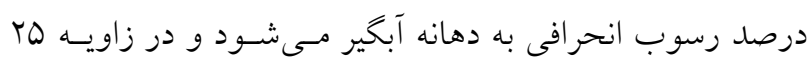
درجه با عدد فرود V/ه، باعث كاهش ه درصد يعنى كمترين اثر در انتقال رسوب به آبخير جانبى را دارد.

\section{تنيجه كيرى}

در اين تحقيق آزمايشها جهت تعيسين درصــ نسـبى رسـوبات انحرافى در قوس •1/ درجه با هدف بررسى تأثير خصوصسيات جريان بر نسبت رسوب انحرافى در شرايط بـا صـفحه و بــدون صفحه مستغرق موازى انجـام كرفـت. متغيرهـاى مـؤثر در ايسن تحقيق عدد فرود و زاويه صفحه بود. نتـايج ايسن تحقيـق نشـان

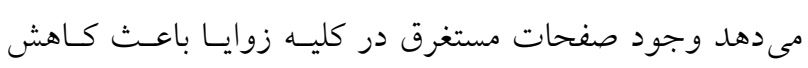

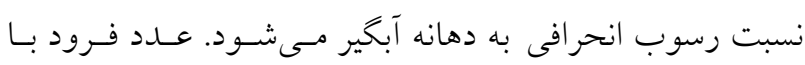
نسبت رسوب ورودى به آبخير نسبت عكس دارد و بـا افزايش

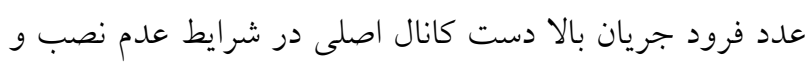

\section{منابع مورد استفاده}

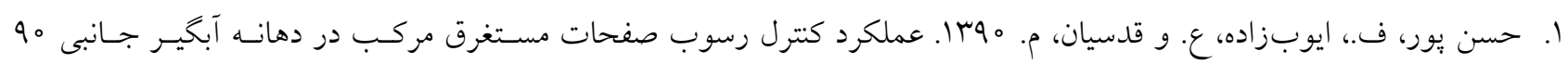

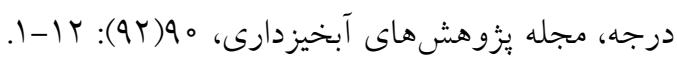

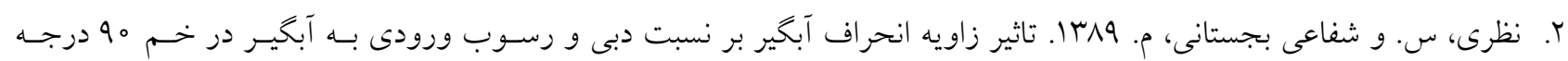

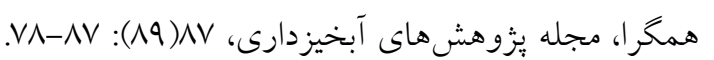

3. Barkdoll, B. D., Hagen, B. L. and Odgaard, J. 1995. Sediment exclusion at hydropower intakes using submerged vanes. Proc. of Waterpower Conference 368-377.

4. Barkdoll, B.D., Ettema, R. and odgaard, J. 1999. Sediment control at lateral diversion: limits and enhancements to vane use. J. of Hydraulic Eng., ASCE 125(8): 862-870.

5. Odgaard, J. and Y. Wang. 1991. Sediment management with submerged vanes. I: Theory. J. of Hydraulic Eng. 117(3): 267-283.

6. Odgaard, A. J. and J. F. Kennedy. 1983. River-bend bank protection by submerged vanes. J. of Hydraulic Eng. 109(8):1161-1173.

7. Oliveto, G. and W. H. Hager. 2002. Temporal evaluation of clear-water pier and abutment scour. J. of Hydraulic Eng. ASCE 128(9): 811-820. 
8. Raudkivi, A. J., R. Ettema. 1983. Clear-water scour at cylindrical piers. J. of Hydraulic Eng. ASCE 109(3): 338-350.

9. Tan, S. K., Yu, G., S. Y. Lim and M. C. Ong. 2005. Flow structure and sediment motion around submerged vanes in open channel. J. of Waterway, Port, coastal and Ocean Eng. 131(3): 132-136. 


\title{
Study of the Effect of the Angle of Submerged Vanes on Sediment Control in Lateral Intake at a 180 Degree River Arc
}

\author{
M. Halvaeifard and A. Masjedi ${ }^{* 1}$ \\ (Received: July 14-2013 ; Accepted: May 16-2016) \\ DOI: $10.18869 /$ acadpub.jstnar.20.78.29
}

\begin{abstract}
One of the methods for sediment control in lateral intake can be application of submerged vanes in front of the inlet. The establishment of submerged vanes in flow path causes a flow diversion toward the inner arc. In this research, the performance of submerged vanes on sediment transport to the inlet at 180 degree of intake has been investigated. Several experiments were carried out in a laboratory channel made of Plexiglas at a 180-degree arc, under clear water condition. In this research a series of experiments were done by inserting several vanes made of Plexiglas in front of lateral intake. Experiments were done by using two rows of parallel vanes with variable angles at four different discharges under two conditions of with and without vanes. In each experiment, the main channel discharge and diversion channel discharge, sediment discharge through the diversion and transmission were measured. The results of research showed that the performance of the parallel submerged vanes in diverting the path of sediments depends on contacted vanes angle by water flow. Also, entering water rate is directly proportional with entering sediment rate and entering sediment rate are increased with the increase of entering water rate at all angles. Suitable performance in reducing the sediment transport to the inlet was observed at an angle of 15 degrees of vanes relative to the axis of water flow. In other words, by increasing the angle relative to the axis of flow, sediment transport to the inlet will be increased.
\end{abstract}

Keywords: Clear water, Lateral intake, Submerged vanes, 180-degree bend.

1. Dept. Agric., Faculty of Water Eng., Ahvaz Branch, Islamic Azad Univ., Ahvaz, Iran.

*: Corresponding Author, Email: drmasjedi.2007@yahoo.com 